\title{
Farm Deaths in North Karelia
}

\author{
MIKKO A. SALO, Ph.D. \\ Professor \\ Department of Social Policy, University of Joensuu, Finland \\ JUHA M. ALHO, Ph.D. \\ Professor \\ Department of Statistics, University of Joensuu, Finland
}

\begin{abstract}
This study examined the effect of farm size on the mortality and survival of Eastern Finnish farms in the late 1990s. Three different dimensions of farm size (i.e. hectares operated, number of milk cows, and hectares of forest) were compared. Data were extracted from administrative records and covered all 4,527 active farms in North Karelia from 1995 to 1998. Results did not support the "disappearing middle size" hypothesis presented by Weiss (1999). Farm size distributions were not bimodal. No empirical evidence was found of a process of polarisation into two "centres of attraction". As a whole, the analysis provides some support for the conclusion that the size of forest holding as measured by hectares of forest owned by farm does not have an independent effect on the likelihood of survival. Its contribution depends on the other variables in the model.
\end{abstract}

\section{Introduction}

Conventionally, demography is defined as a statistical study of human populations only (see e.g., Merriam-Webster Collegiate Dictionary). In their recent book, "The Demography of Corporations and Industries", Carroll and Hannan (2000), however, give reasons why other sociological specialties should be interested in this paradigm as well. As Knoke $(2000,838)$ says, Carroll and Hannan "effectively integrate the conceptual framework, theoretical propositions, data collection procedures, statistical tools, and research methods essential for investigating the founding, growth, decline, transformation, and mortality of organizational populations". By 'corporation', they mean not only businesses studied by economists or political parties and interest groups analysed by political scientists but also "the myriad types 
of organisations and associations that interest sociologists" (Carroll and Hannan 2000, xix).

In this paper, we follow the research program proposed by Carroll and Hannan, and we study statistically the size and density, distribution, and vital statistics of a type of corporations - namely, farms. We are interested in the discussion about recent trends in farm size distributions in developed countries. For example, Weiss (1999) has observed that his analysis of Upper Austrian farm households supports the perception of a "disappearing middle" in farm size distribution. He found evidence of a process of polarisation into two "centres of attraction". Small farms appeared to grow faster toward some particular size than farms at or above this standard size. And, simultaneously, medium-sized and large farms seemed to have a tendency to cluster around their own optimum size. Nevertheless, Wolf and Sumner (2001) analysed U.S. dairy farm size distributions and found that they, contrary to broad expectations, seem not to be bimodal.

Wolf and Sumner (2001) used non-parametric density estimation techniques, whereas Weiss (1999) wanted to see the extent to which Gibrat's Law of Proportionate Effects applies to all farm-sizes (see also McCloughan 1995 and Sutton 1997). He proposed an explanation based on the assumption that there are two economically optimal farm sizes: one for part-time farms and another for fulltime farms. This paper is concerned with the effect farm survival has on farm size distribution. We are going to analyse empirical evidence on the structural dynamics of farm demography. In particular, we examine the mortality of farms in North Karelia, Finland, and we investigate the factors associated with their likelihood of survival in the late 1990s.

In Finland, recent national statistics seem to indicate that the probability of closing down is highest among medium-size farms (see e.g. SVT 2001:22). There have been, however, very few local studies on the birth, growth and death of farms. North Karelia is one of the numerous stagnating peripheral and rural areas of present-day Europe. Since 1960, its population had declined from 207,700 to 175,100 in 1999 (a decrease of $15.7 \%$ ). Most of North Karelia's agricultural production comes from primary production farms engaged in traditional farming such as agriculture, forestry and small-scale specialist farming. In the years 1990-2000, fifty per cent of active farms went out of business.

Thus, if North Karelia is compared to Upper Austria, many obvious similarities and dissimilarities can be noticed. North Karelia is a small Eastern province (6.4 percent of Finland's area and 3.5 percent of its population). It is located in the periphery of a country, Finland, which is itself in the periphery of the European Union. Upper Austria, in turn, is the third largest state of a central nation of Middle Europe (14.3 percent of area and 17.2 percent of population). 
Farming, as it is practiced in Upper Austria, is predominantly a family business in North Karelia. In both places, the arable land per farm is above 20 hectares. Both areas belong to the milk producing regions. According to Weiss (1999) 19 percent of all farms in Austria are located in Upper Austria but they own 29 percent of all livestock in Austria. In North Karelia, the respective shares are 4 percent and 7 percent. This means that almost 50 percent of farms have milk cows in North Karelia whereas the average share of milk farms in Finland is around 30 percent (see Ministry of Agriculture ... 2001).

Unfortunately, one of the important facts about farming in North Karelia is not available. Namely, we do not know the number of part-time farms in North Karelia. We know that one-third of farms are involved in other forms of entrepreneurship in North Karelia but there are, as far as we know, no statistics on time spending among farmers and their spouses as there are in Austria. According to Weiss (1999) almost 70 percent of farms are part time in Upper Austria. With respect to North Karelia, we have to use a rough estimation. When interviewed, experts at the North Karelian Center of Rural Development estimated that the figure might be somewhat lower in North Karelia.

\section{Data}

Our data consist of farm records provided by the Ministry of Agriculture and Forestry. For each year, the Ministry collects extensive information on farm characteristics such as acres under cultivation, shares of different crops in the cultivation and the number of livestock. We had records of North Karelian farms for the years 1995, 1996, 1997 and 1998.

Table 1. Vital events among North Karelian farms, 1995-1998.

\begin{tabular}{ccccc}
\hline Year & Total number of farms & Farm deaths & Survived farms & Farm births \\
\hline 1995 & 4,527 & 544 & 3,983 & 68 \\
1996 & 4,053 & 251 & 3,802 & 70 \\
1997 & 3,870 & 247 & 3,623 & 82 \\
1998 & 3,705 & & & \\
\hline
\end{tabular}

In 1995, an especially large number of farms (544 farms or 12 percent) went out of business in North Karelia (see Table 1). At the same time, only 68 new farms were established. Although the number of farm exits went down concurrently with a slight increase in the numbers of new farms, the levels of farm mortality greatly exceeded the natality. The number of active farms (i.e., farms receiving financial support) dropped from 4,527 to 3,705 between 1995 and 1998. This is a drop of more than 18 percent. 
The total number of hectares operated was about 84,500 ha (see Table 2). In 1995, about 23.9 percent of the cultivated area of a North Karelian farm was under grain and 72.9 percent was under grass. By 1998, the share of grain had increased to 29.6 percent and the share of arable area under grass had been reduced to 59.3 percent.

The number of farms that have milk cows has been shrinking from 2,453 in 1995 to 2,292 in 1998 (cf. Zepeda 1995). At the same time, their share of the total number of farms went down from 54.2 to 52.0 percent, and the median number of milk cows grew from 11.0 to 12.0. Both the skewness and the kurtosis of milk cow distribution increased considerably. The maximum number of milk cows on farm more than doubled. It was 44 in 1995 and 89 in 1998.

Table 2. Selected characteristics of farm size distributions in North Karelia, 1995 and 1998.

\begin{tabular}{lcc}
\hline Variable & 1995 & 1998 \\
\hline Farm size in hectares operated & & \\
$\quad$ Arithmetic mean & 18.86 & 22.82 \\
Median & 16.14 & 18.70 \\
Std. deviation & 13.52 & 16.61 \\
No. of farms & 4,527 & 3,705 \\
& & \\
Dairy farms ${ }^{1}$ & & \\
Arithmetic mean of milk cows & 11.5 & 13.4 \\
Median of milk cows & 11.0 & 12.0 \\
Std. deviation of milk cows & 5.85 & 7.58 \\
No. of dairy farms & 2,453 & 1,925 \\
(\% of all farms) & $(54.2)$ & $(52.0)$ \\
& & \\
Forest area owned by farms in hectares & 48.39 & 52.57 \\
Arithmetic mean & 37.90 & 41.20 \\
Median & 42.42 & 46.27 \\
Std. deviation & 4,431 & 3,587 \\
No. of forest owning farms & $(97.9)$ & $(96.8)$ \\
(\% of all farms) &
\end{tabular}

${ }^{1}$ All farms with milk cows were included.

The average size of forest holdings owned by farms grew slightly between 1995 and 1998. The arithmetic mean increased from 48.39 hectares to 52.57 hectares and the median from 37.90 hectares to 41.20 hectares (see Table 2). 


\section{Analyses and Results}

Distributions of hectares operated were right-skewed in North Karelian farms in 1998 (see Figure 1). The kurtosis had flattened. Forest hectare distributions were almost similar in form. Their skewness and peakedness had gone down a little bit. It is apparent, however, that the distributions were characterised by one peak only (see Figure 1).

The development of milk cow distribution has been somewhat different. The right tail has become much longer. In 1995, the biggest number of milk cows on farm was 44 . Three years later it was 89 and there were 10 dairy farms (out of 1,925) that had more than 50 milk cows. The arithmetic mean of the number of milk cows was almost equal to the median in 1995. By 1998, the mean had grown bigger than the median (13.4 and 12.0, respectively) and the dispersion measured by standard deviation had increased from 5.85 to 7.58 . Nevertheless, this does not mean that the transformation resulted in two peaks.

There are two indices, namely the SCV (Squared Coefficient of Variation) and the MLD (Mean Log Deviation), that are used to measure inequality of income distributions:

$$
\begin{gathered}
S C V=\frac{\operatorname{var}\left(X_{i}\right)}{\mu^{2}}=\frac{1 \sum_{i}\left(X_{i}-H\right)^{2}}{\mu^{2}} \\
M L D=\frac{\sum_{i} \ln \left(\frac{\mu}{X_{i}}\right)}{n}
\end{gathered}
$$

where $X_{i}$ is the share of an individual farm $i(i=1,2, \ldots n$, where $n$ is the total number of farms); and where $\mu$ is the arithmetic mean of shares per farm. It is known that "the MLD is more sensitive to changes at the bottom of the distribution, while the opposite occurs for the SCV" (see e.g. Burniaux et al. 1998, 85). 
Figure 1. Farm size distributions as measured in hectares operated, hectares of forest and number of milk cows.
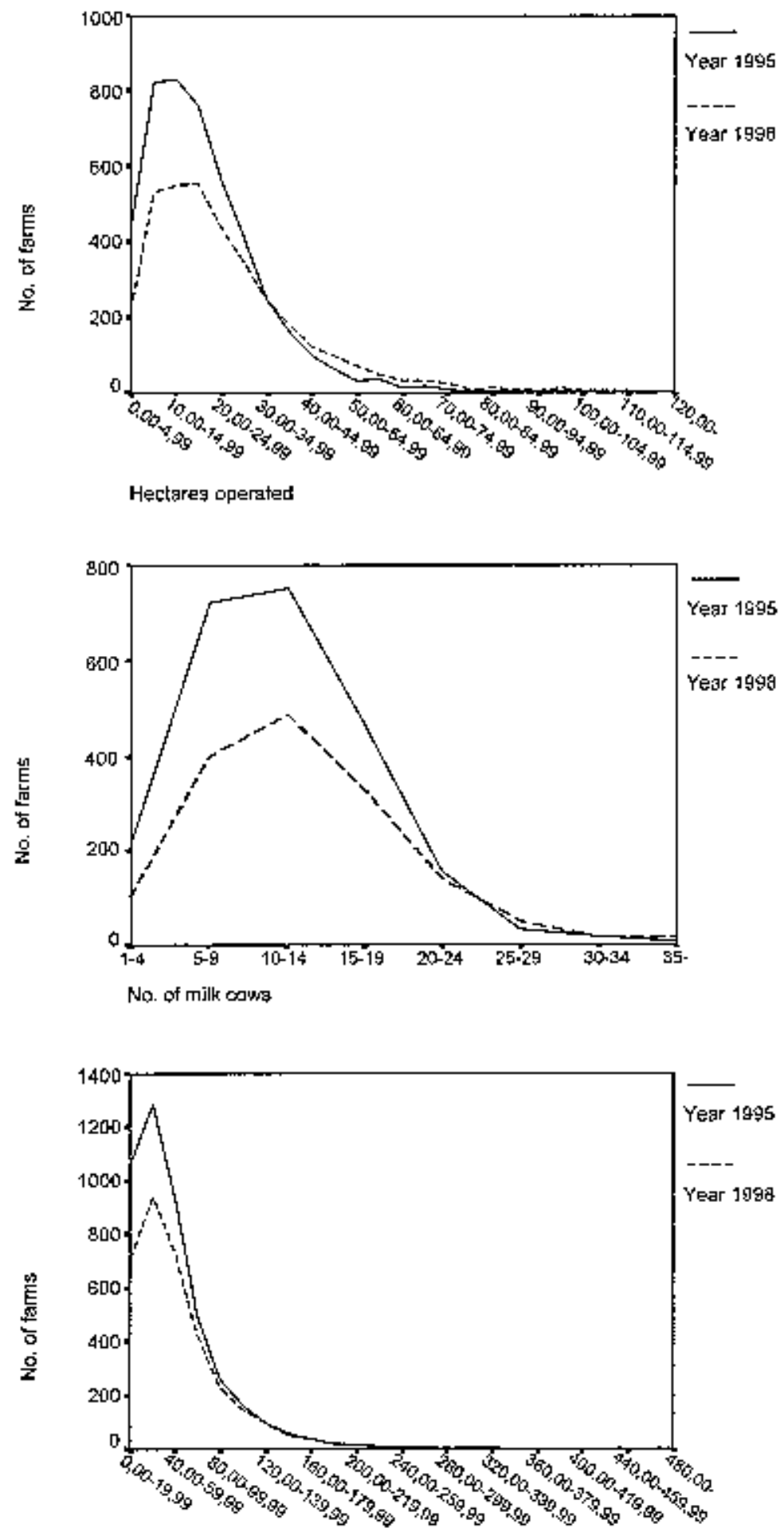

Hedtares of lorest 
Table 3. Inequalities in farm size distributions measured as the Mean Log Deviation (MLD) and the Squared Coefficient of Variation (SCV).

\begin{tabular}{lll}
\hline Farm size measure & 1995 & 1998 \\
\hline Hectares operated & & \\
$\quad$ MLD & 0.25 & 0.28 \\
SCV & 0.51 & 0.60 \\
Number of milk cows ${ }^{1}$ & & \\
MLD & 0.16 & 0.17 \\
SCV & 0.26 & 0.32 \\
& & \\
Hectares of forest & & \\
MLD & 0.39 & 0.40 \\
SCV & 0.77 & 0.78 \\
\hline
\end{tabular}

${ }^{1}$ All farms with milk cows were included.

It seems that the distribution of hectares of forest has changed less than the two other farm size measures (see Table 3). The inequality of the distribution of milk cows has remained almost unchanged when measured by the MLD which is responsive to changes of the bottom of the distribution. The MLD indices are 0.16 and 0.17 . The SCV indices show, however, that inequalities had increased (0.26 in 1995 and 0.32 in 1998) which is most probably due to the fact that the right tail of distribution has extended. 
Figure 2. Farm mortality by hectares operated, number of milk cows and hectares of forest.

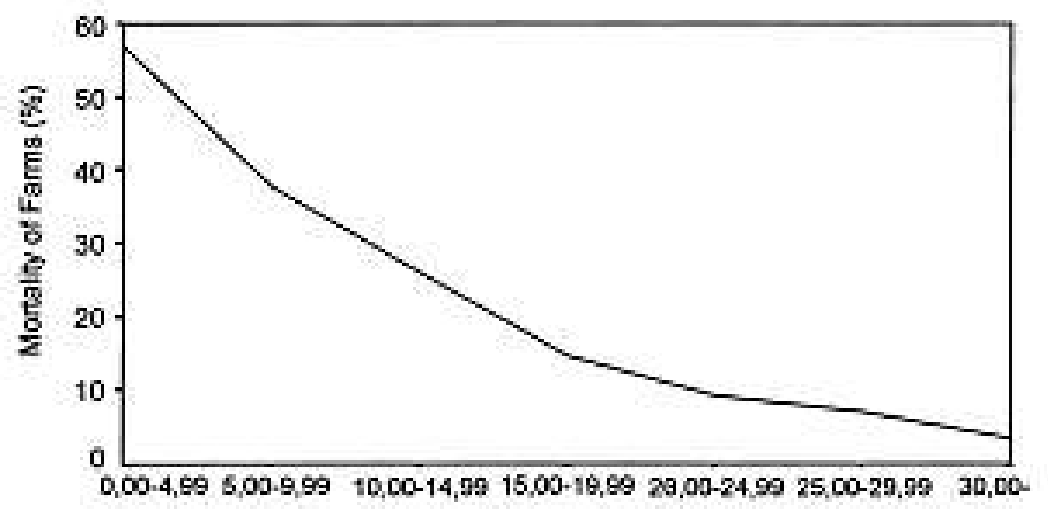

Hectares operated
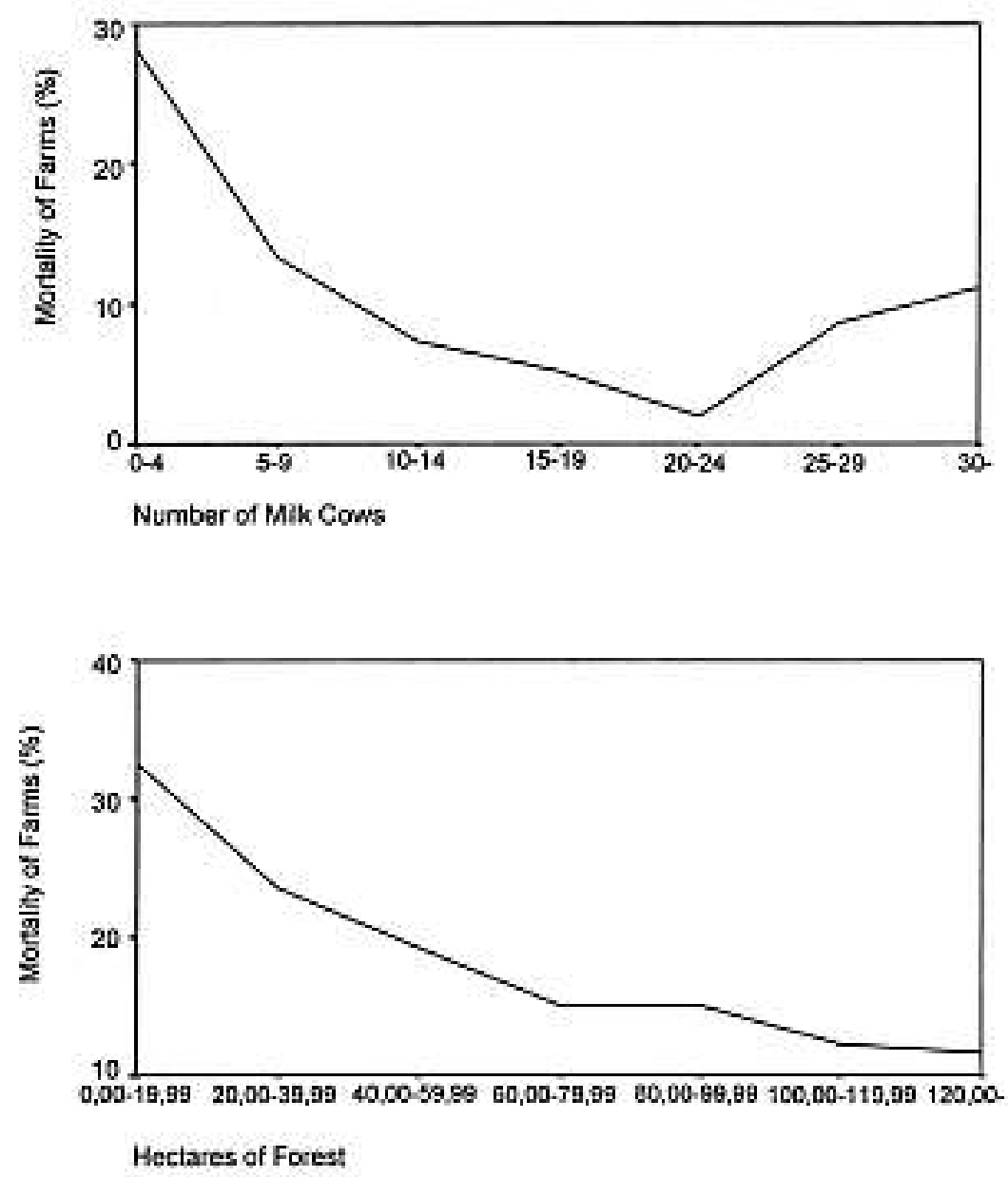
Inequalities in the distribution of hectares operated have seemingly widened at both ends. The MLD has increased from 0.25 to 0.28 and the SCV has jumped from 0.51 to 0.60 . The number of farmers cultivating larger areas has become considerably bigger. The percentage of farms with at least 70 hectares operated became threefold between years 1995 and 1998 .

In the 1990s, mortality of farms has depended on farm size in North Karelia. The smaller the farm, the higher has been the likelihood of exit. This is especially clear when size is measured in hectares of arable land or forest (see Figure 2). Almost two-thirds of farms with less than 5 hectares of land under cultivation or one-third of farms that own less than 20 hectares forest closed down in 1995-1998. The association between farm mortality and the number of milk cows on the farm was, however, a little more complicated. The probability of exit decreased monotonically up to the size of 20-24 hectares, and started to grow again. The risk of being put out of business was only 1.9 percent among the dairy farms with 20-24 milk cows but approximately 10 times higher among dairy farms that had 30 or more milk cows.

In 1995-1998, smaller North Karelian farms had a higher probability of growth than bigger farms (see Figure 3). Consequently, zero growth or negative growth was more likely among bigger farms than among smaller farms. There seems to be no tendency toward bimodal polarisation. A majority of farms with more than 20 hectares of cultivated land did not grow in terms of hectares operated in 19951998. A similar equivalent point was found with 10-14 milk cows: the more the number of milk cows exceeded this point, the smaller the proportion of farms that increased their cattle.

Nevertheless, the dependency between type of growth seemed to be different when the size of the farm was measured in hectares of forest (see Figure 3). The proportion of growing farms was a decreasing function on the size of the farm without any equivalent point with the curve showing that the percentage of farms did not grow in terms of forest holdings. 
Figure 3. Percentage of farms of two different types of growth (positive or zero growth and negative) in terms of all three farm size measures.
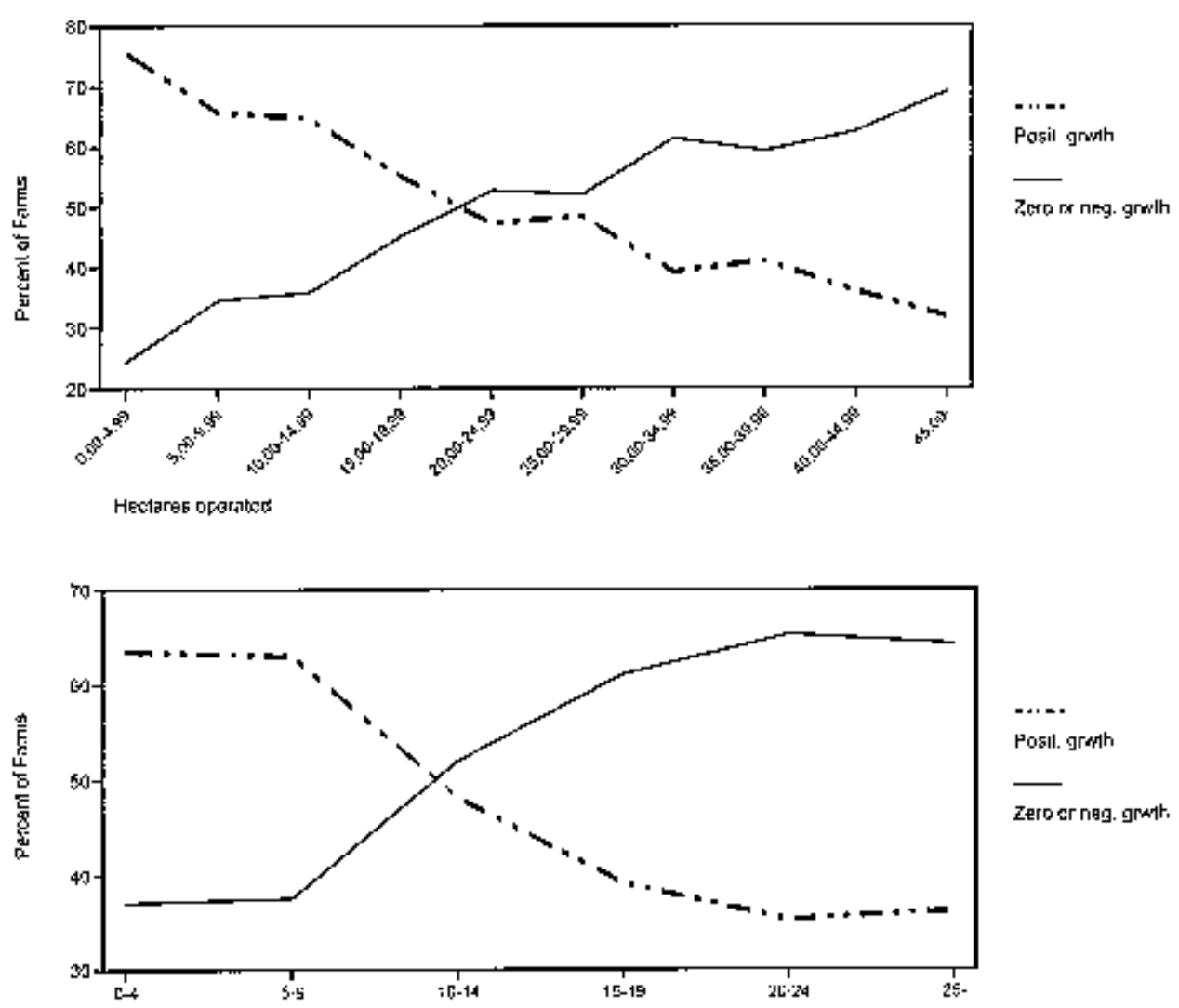

|Humber al bâk Cows

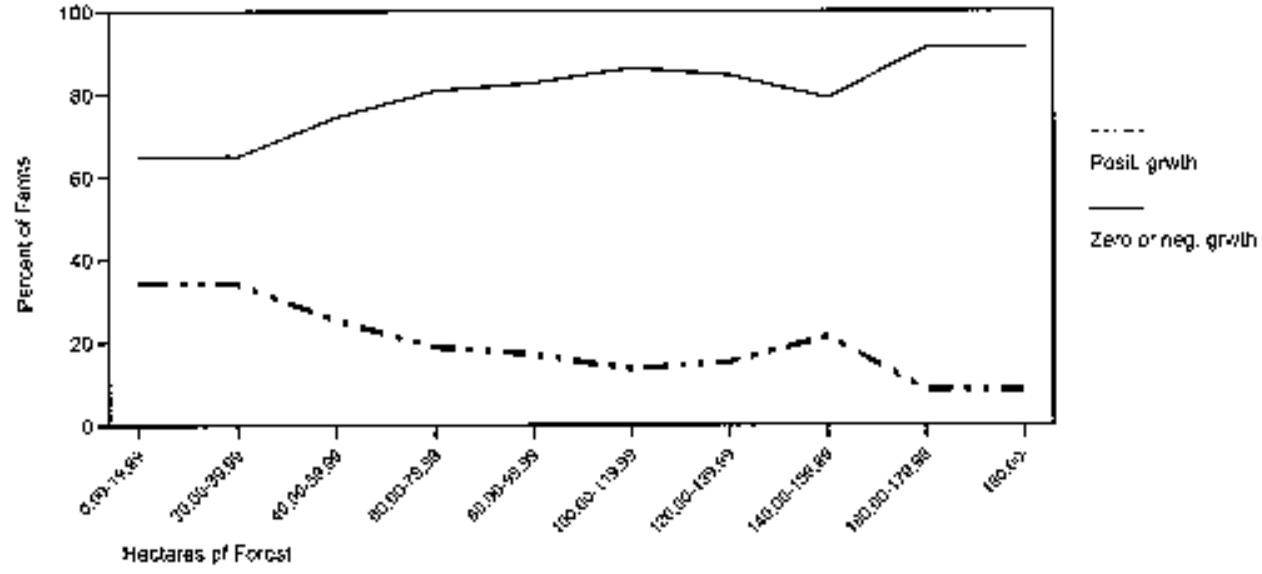


The three farm size measures are associated with farm survival from 1995 to 1998 in a somewhat complicated way. The results of the logistic regression analyses are shown in Table 4. The more hectares of cultivated land a farm had, the lower the probability of its going out of business in the years when the effects of the other two measures were controlled. The odds ratio was 1.165 (95\% CI 1.135-1.195) in Model 1, which had hectares of forest holdings and number of milk cows as independent variables.

Table 4. Farm size measures associated with farm survival from 1995 to 1998 in logistic regression analyses.

\begin{tabular}{|c|c|c|c|c|}
\hline & $\begin{array}{l}\text { Model } 1 \\
\text { OR } \\
(95 \% \mathrm{Cl})\end{array}$ & $\begin{array}{l}\text { Model } 2 \\
\text { OR } \\
(95 \% \mathrm{Cl})\end{array}$ & $\begin{array}{l}\text { Model } 3 \\
\text { OR } \\
(95 \% \mathrm{Cl})\end{array}$ & $\begin{array}{l}\text { Model } 4 \\
\text { OR } \\
(95 \% \mathrm{Cl})\end{array}$ \\
\hline Hectares operated & $\begin{array}{l}1.165^{\star * *} \\
(1.135-1.195)\end{array}$ & $\begin{array}{l}1.111^{* * *} \\
(1.099-1.123)\end{array}$ & $\begin{array}{l}1.113^{* * *} \\
(1.098-1.128)\end{array}$ & $\begin{array}{l}1.107^{\star \star *} \\
(1.092-1.122)\end{array}$ \\
\hline No. of milk cows & $\begin{array}{l}0.971 \\
(0.940-1.003)\end{array}$ & & & \\
\hline $\begin{array}{l}\text { Milk cows on farm: } \\
\text { No /Yes }\end{array}$ & & & $\begin{array}{l}1.684^{* * *} \\
(1.393-2.034)\end{array}$ & \\
\hline \multicolumn{5}{|l|}{ No. of milk cows } \\
\hline $1-4 / 5-$ & & & & $\begin{array}{l}1.954^{* * *} \\
(1.593-2.398)\end{array}$ \\
\hline Hectares of forest & $\begin{array}{l}1.000 \\
(0.996-1.004)\end{array}$ & $\begin{array}{l}1.002 \\
(1.000-1.004)\end{array}$ & $\begin{array}{l}1.002 \\
(0.999-1.004)\end{array}$ & $\begin{array}{l}1.002 \\
(0.999-1.004)\end{array}$ \\
\hline-2 Log likelihood & $1,279.317$ & $3,948.984$ & $3,205.082$ & $3,191.983$ \\
\hline No. of cases & 2,342 & 4,402 & 4,170 & 4,170 \\
\hline
\end{tabular}

Note: $\mathrm{OR}=$ odds ratio; $\mathrm{Cl}=$ confidence interval;

${ }^{*} p<0.05 ;{ }^{* *} p<0.01 ;{ }^{* * *} p<0.001$.

The area of forest holdings, on the contrary, seemed to have no statistically significant contribution to the likelihood of survival when the other two dimensions of farm size were controlled. Its odds ratio was very close to unity in our regression analyses (see Table 4).

The association between surviving and the number of milk cows on the farm seems not to be linear. In Model 1 , the number of milk cows was not associated with survival (see Table 4). The odds ratio was 0.971 (95\% CI 0.940-1.003). Model 3 shows, however, that the factor that indicates whether there were milk cows on a farm or not was very strongly associated with farms' survival. The odds ratio was 1.684 (95\% CI 1.393-2.034). And, furthermore, it seemed to be important for survival that there were at least 5 milk cows. The odds ratio was 1.954 (95\% CI $1.593-2.398)$. 


\section{Discussion}

This paper set out to explore some of the factors that affect mortality of farms under changing socio-economic conditions and across the recent stages of structural development. Instead of utilising conventional economic and sociological approaches, we have employed a demographic framework and theoretical thinking in studying a non-human population. As suggested by Carroll and Hannan (2000) we have analysed the transformation and mortality of an organisational population demographically.

Our study of farm survival in North Karelia between 1995 and 1998 serves as a sort of pilot study. It permits us to disentangle different measures of farm size (i.e. hectares under cultivation, number of milk cows on farm and the area of forest holdings owned by individual farms) as correlates of farm mortality. In this administrative data we found that: (1) there was no indication of farm size distributions being bimodal neither in 1995 nor in 1998; (2) there seemed to be no tendency toward bimodal polarisation in terms of size-dependent differences in mortality of farms; (3) there was no empirical evidence to support the hypothesis of "disappearing middle-sized farms".

Thus, our results conflict with observations made by Weiss (1999) on a bimodal shape of farm size distributions in Upper Austria. They are, however, in accordance with the findings that Wolf and Sumner (2001) reported concerning the distributions of U.S. dairy farms. It seems that the development in North Karelia is likely to lead to a general growth of surviving farms rather than a clustering around two (or more) "centres of attraction". Our analyses show that this is especially apparent among North Karelian dairy farms. Their size distribution grew its right tail substantially.

The most striking observation is, however, the minor role that forest holding seem to play in the survival of a North Karelian farm in the late 1990s. Contrary to general belief, the hectares of forest owned by a farm appears, at best, to be only weakly related to the likelihood of survival. In fact, the logistic regression analyses provide some support for the conclusion that the size of forest holdings as measured by hectares of forest owned by a farm does not have an independent effect on the likelihood of survival. Its contribution depends on the other variables in the model. Further studies are needed to test competing hypothetical explanations on this unexpected finding.

Further studies are also needed to explain why there seems to be no bimodality in the shape of farm size distributions in North Karelia. If the role of part-time farming is as crucial as Weiss (1999) suggests, then one explanation is that there are 'too 
few' part-time farmers in North Karelia. Collecting data of how the North Karelian farmers and their spouses spend their time is therefore required.

\section{References}

Burniaux, Jean-Marc, Thai-Thanh Dang, Douglas Fore, Michael Förster, Marco Mira d'Ercole, and Howard Oxley. 1998. Income distribution and poverty in selected OECD countries. Economic Department Working Papers No. 189. Paris: OECD.

Carroll, Glenn R. and Michael T. Hannan. 2000. The demography of corporations and industries. Princeton, N.J.: Princeton University Press.

Knoke, David. 2000. The demography of corporations and industries (book review). American Journal of Sociology 106(3): 838-341.

McCloughan, Patrick. 1995. Simulation of concentration development from modified Gibrat growth-entry-exit processes. The Journal of Industrial Economics 43(4):405-433.

Merriam-Webster Collegiate Dictionary, [online]. Available from: $\leq$ http://www.m-w.com/cgi-bin/dictionary $>$.

Ministry of Agriculture and Forestry. Agriculture and countryside. [online]. Helsinki, Finland. [Cited 10 August 2001]. Available from: $\leq \mathrm{http}: / /$ www.mmm.fi/ english/agriculture/ $>$.

Sutton, John. 1997. Gibrat's legacy. Journal of Economic Literature 35(1): 40-59.

SVT 2001:22. The statistics of agricultural enterprises and income 1991. Statistics Finland, Helsinki.

Weiss, Christoph R. 1999. Farm growth and survival: Econometric evidence for individual farms in Upper Austria. American Journal of Agricultural Economics 81(1):103-116.

Wolf, Christopher A. and Daniel A. Sumner. Are farm size distributions bimodal? Evidence from Kernel density estimates of dairy farm size distributions. American Journal of Agricultural Economics 83(1): 77-88.

Zepeda, Lydia. 1995. A symmetry and nonstationarity in the farm size distribution of Wisconsin milk producers: An aggregate analysis. American Journal of Agricultural Economics 77(4): 387-843. 